\title{
Aerodynamic Design of a Tailless Aeroplan
}

J. Friedl

The paper presents an aerodynamic analysis of a one-seat ultralight (UL) tailless aeroplane named L2 $k$, with a very complicated layout. In the first part, an autostable airfoil with a low moment coefficient was chosen as a base for this problem. This airfoil was refined and modified to satisfy the design requirements. The computed aerodynamic characteristics of the airfoils for different Reynolds numbers (Re) were compared with available experimental data. XFOIL code was used to perform the computations. In the second part, a computation of wing characteristics was carried out. All calculated cases were chosen as points on the manoeuvring and gust envelope. The vortex lattice method was used with consideration of fuselage and winglets for very complicated wing geometry. The PMW computer program developed at IAE was used to perform the computations. The computed results were subsequently used for structural and strength analysis and design.

Keywords: aviation, aerodynamics, tailless aeroplane, airfoil, wing.

\section{Introduction}

UL aircraft have recently became very popular and relatively simple to build and operate. However this process does not mean that the design and analysis of such aeroplanes is

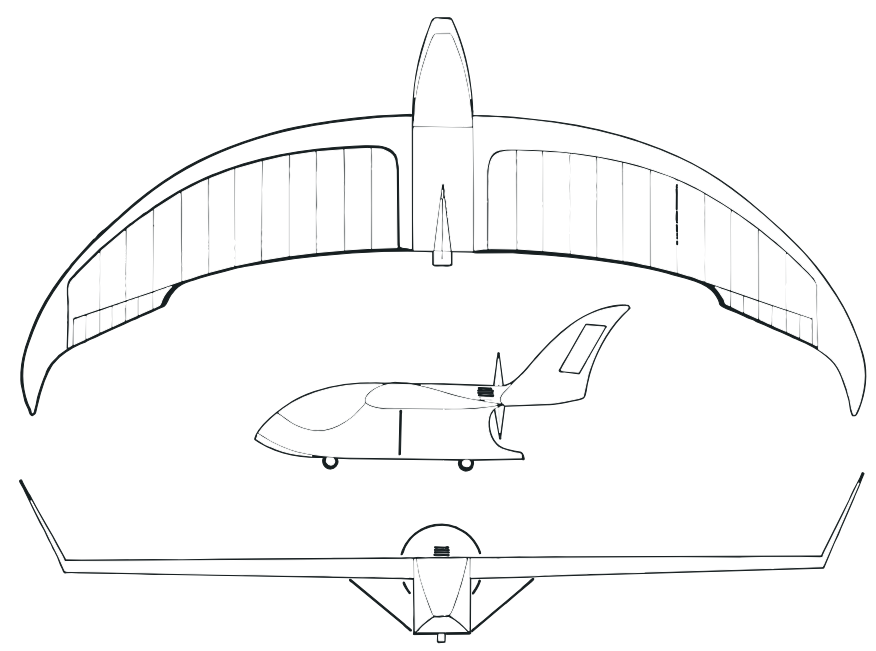

Fig. 1: L2k layout

Table 1: L2k design parameters

\begin{tabular}{|l|c|c|}
\hline Parameter & Value & Unit \\
\hline Max. take off weight & 300 & $\mathrm{~kg}$ \\
\hline Length & 5.3 & $\mathrm{~m}$ \\
\hline Height & 2.1 & $\mathrm{~m}$ \\
\hline Total span & 11.71 & $\mathrm{~m}$ \\
\hline Wing span & 10.8 & $\mathrm{~m}$ \\
\hline Dihedral & 0 & $\mathrm{deg}$ \\
\hline Sweep & variable & \\
\hline Wing area & 16.8499 & $\mathrm{~m}^{2}$ \\
\hline Aspect ratio & 6.9223 & 1 \\
\hline
\end{tabular}

unsophisticated. The main aspect, that has an impact on the design simplicity, is the configuration of lifting surfaces and its geometry. The L2k is a UL, one-seat, high-wing aeroplane with an almost parabolic wing layout and mixed construction. The aeroplane has a tailless configuration with rudders on the tip of the wing (winglets) and ailerons likewise with a coupled function as a horizontal tail. An aerodynamical analysis involves investigating the airfoil characteristics for two different values of relative thickness and computations of wing characteristics. The L2k is designed according to German $\mathrm{BFU}$ requirements for UL aircraft.

\section{Notation}

\begin{tabular}{|c|c|c|}
\hline$\alpha$ & {$[\mathrm{deg}]$} & Angle of attack \\
\hline$\alpha_{0}$ & {$[\mathrm{deg}]$} & Zero lift angle \\
\hline$C_{\mathrm{k}}^{*}$ & {$[1]$} & Coefficients for wing \\
\hline$C D$ & {$[1]$} & Drag coefficient \\
\hline$C D_{\mathrm{i}}$ & {$[1]$} & Induced drag coefficient \\
\hline$C L$ & {$[1]$} & Lift coefficient \\
\hline$C L_{\alpha}$ & {$\left[\mathrm{rad}^{-1}\right]$} & Lift curve slope \\
\hline$C L_{\max }$ & {$[1]$} & Max. lift coefficient \\
\hline$C M$ & {$[1]$} & Moment coefficient ( 0.25 chord) \\
\hline$C M_{0 \text { as }}$ & {$[1]$} & CM of wing for zero lift angle \\
\hline$C M_{\alpha}$ & {$\left[\mathrm{rad}^{-1}\right]$} & Moment curve slope \\
\hline$\delta C L_{\alpha}$ & {$\left[\mathrm{rad}^{-1}\right]$} & $\mathrm{CL}_{\mathrm{k}}$ difference \\
\hline$\varepsilon_{\mathrm{T}}$ & {$[\mathrm{deg}]$} & Geometric twist angle of wing tip airfoil \\
\hline$\varepsilon_{W}$ & {$[\mathrm{deg}]$} & Geometric twist angle of winglets \\
\hline$L$ & - & Left aileron \\
\hline$n$ & {$[1]$} & g-loading \\
\hline$R$ & - & Right aileron \\
\hline $\operatorname{Re}$ & {$[1]$} & Reynolds number \\
\hline
\end{tabular}




$\begin{array}{lll}V_{\mathrm{a}} & {[\mathrm{kph}]} & \text { Speed of turn } \\ V_{\mathrm{d}} & {[\mathrm{kph}]} & \text { Maximum speed } \\ x, y, z & & \text { coordinate axis }\end{array}$

\section{Airfoil analysis}

The first step during the design of lifting surfaces is the choice of an airfoil. An airfoil with low moment coefficient is needed for tailless aeroplanes to ensure stability during flight. The N60R airfoil was chosen as the base for further investigation. This airfoil belongs to the family of autostable profiles with a slightly " $\mathrm{S}$ " shape of the mean curve, which has a direct impact on the value of the moment coefficient. Because the original airfoil coordinates were too rough they had to be refined and an airfoil named N60R124 with a relative thickness of $12.4 \%$ was developed. By modification the N60R124 to a relative thickness of $15.0 \%$ the N60R150 airfoil arose and was used at the root wing section. The two airfoils have identical mean curves with maximum relative camber $2.7 \%$, so a similar moment coefficient value was expected.

\subsection{Used program}

XFOIL version 5.7 code was used to perform the computations. According to [2] the inviscid formulation built in this program is a second order panel method with a finite trailing edge modelled as a source panel. This formulation is closed with the explicit Kutta-Joukowski condition. The viscous formulation is based on the two-equation lagged dissipation
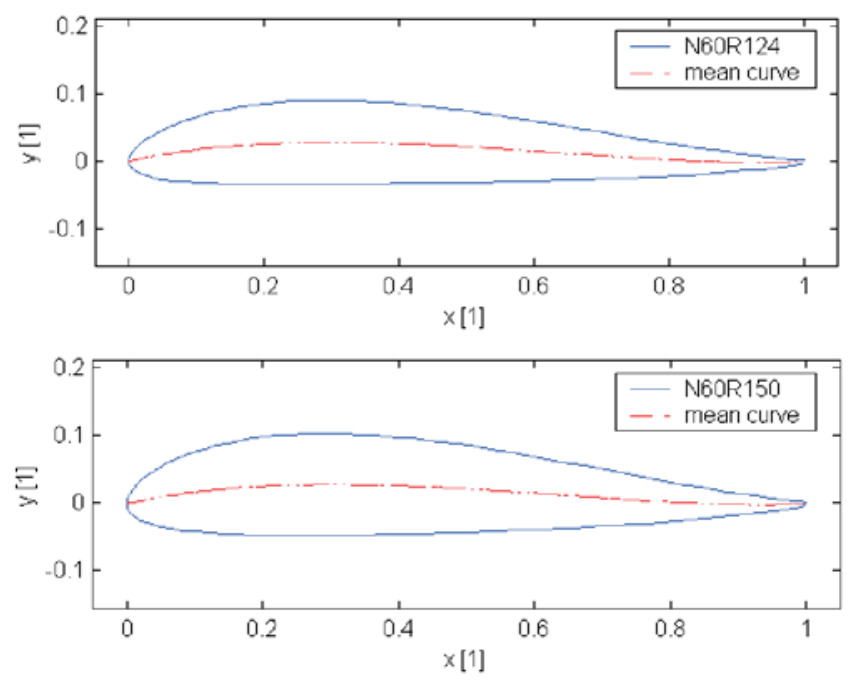

Fig. 2: Airfoils N60R124 and N60R150

integral boundary layer model and an envelope $\mathrm{e}^{\mathrm{n}}$ transition criterion. The solution of the boundary layers and wake is interacted with the incompressible potential flow via the surface transpiration model. The drag is computed from the wake momentum thickness far downstream.

\subsection{Experimental data and computation comparison}

At the beginning, the computation for $\mathrm{Re}=168000$ was done and compared with available experimental data from [1]. There was no information about the measurement conditions, so it was decided to leave the settings of the solution parameters in XFOIL at default values. The turbulence intensity was set to $0.07 \%$. Comparisons for lift and moment curves are shown in Fig. 3 and 4. For unknown parameters, e.g. the roughness, turbulence intensity and correction at measurement space, the comparison was not conclusive.

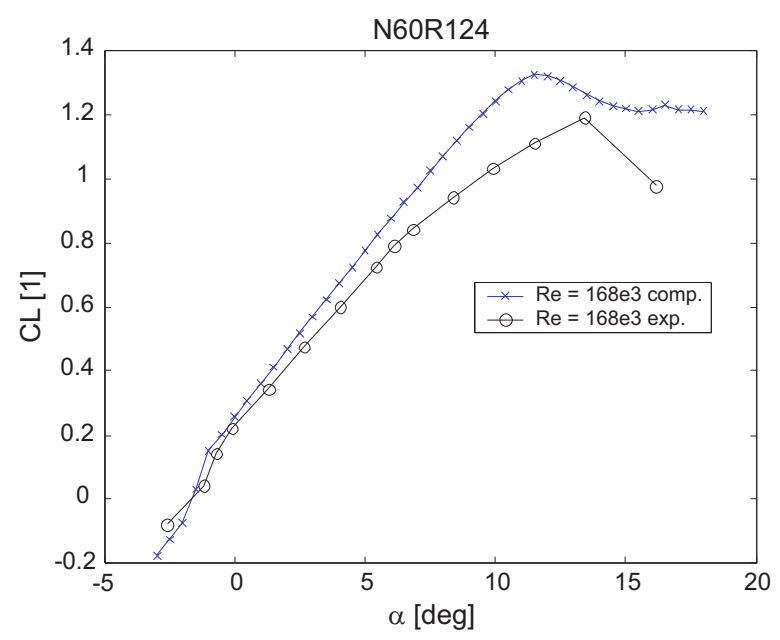

Fig. 3: Lift curve comparison

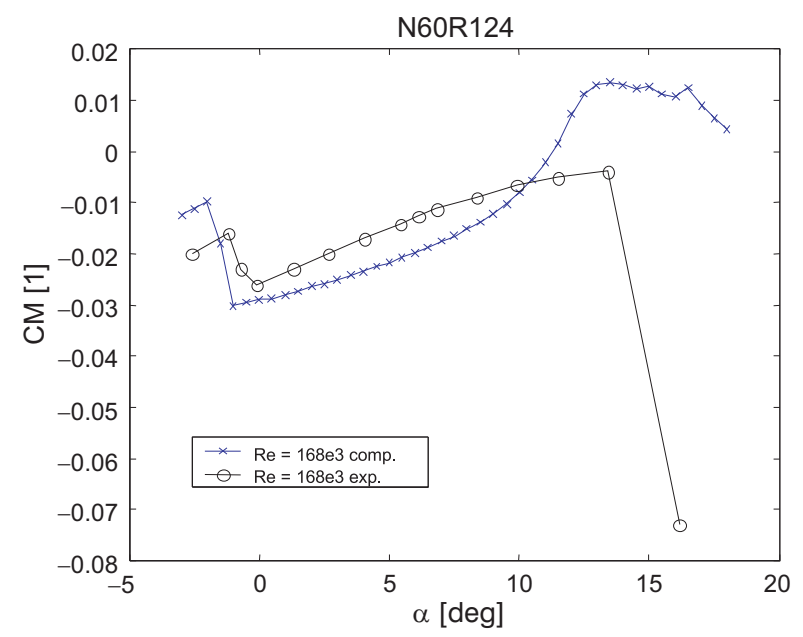

Fig. 4: Moment curve comparison

\subsection{Aerodynamic characteristics of airfoils for different Re numbers}

Computations of the aerodynamic characteristics of airfoils N60R124 and N60R150 were done for the considered range of Re number for the root and tip section for the designed speed range and $0 \mathrm{~m}$ of ISA. The values of zero angle attack and lift curve slope were determined by the least squares method from the lift curves. 


\section{Airfoil N60R124}

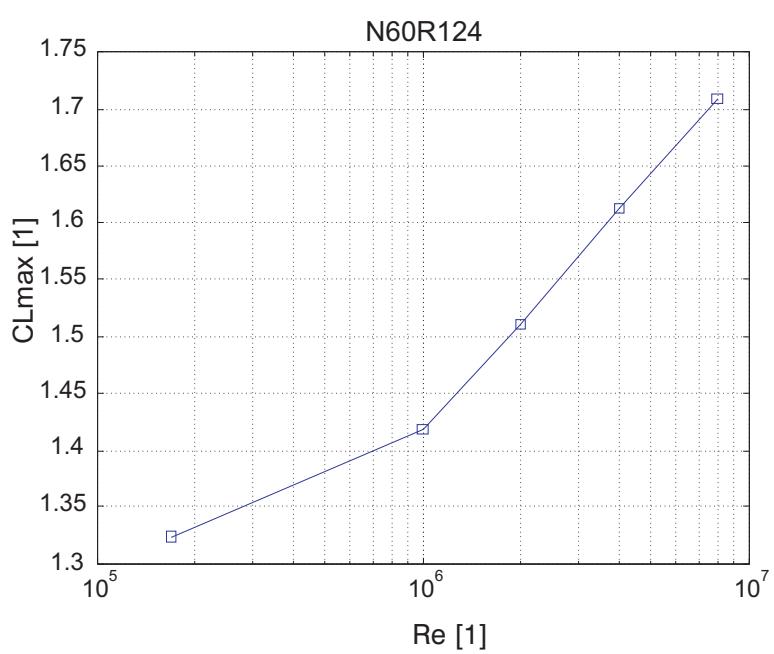

Fig. 5: Computed variation of $C L_{\max }$ with increasing Re number

Table 2: Aerodynamic characteristics of N60R124, Re range

\begin{tabular}{|c|c|c|c|}
\hline $\begin{array}{c}\operatorname{Re} \\
{[1]}\end{array}$ & $\begin{array}{c}\alpha_{0} \\
{[\mathrm{deg}]}\end{array}$ & $\begin{array}{c}C L_{\alpha} \\
{\left[\mathrm{rad}^{-1}\right]}\end{array}$ & $\begin{array}{c}C L_{\max } \\
{[1]}\end{array}$ \\
\hline 168000 & -0.36 & 5.226 & 1.324 \\
\hline 1000000 & -0.58 & 5.998 & 1.418 \\
\hline 2000000 & -0.68 & 6.258 & 1.511 \\
\hline 4000000 & -0.83 & 6.492 & 1.612 \\
\hline 8000000 & -1.02 & 6.642 & 1.710 \\
\hline
\end{tabular}

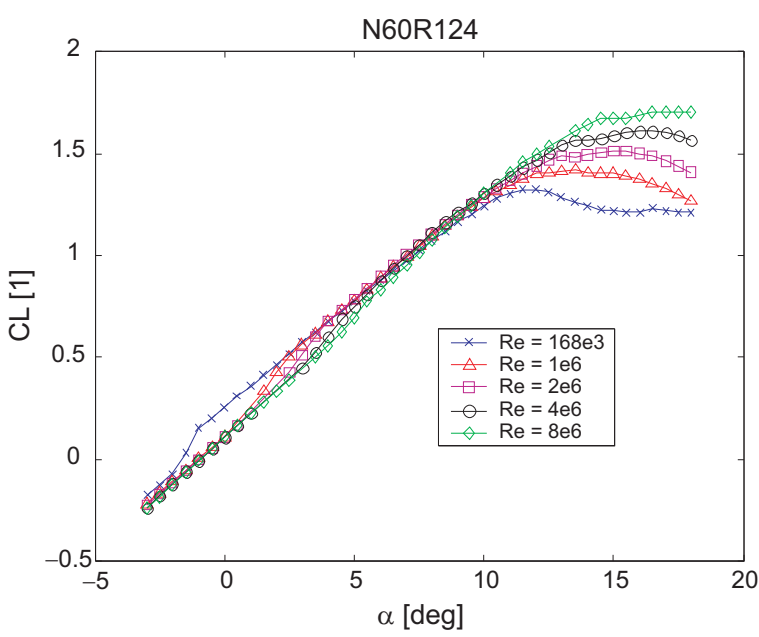

Fig. 6: Computed lift curves

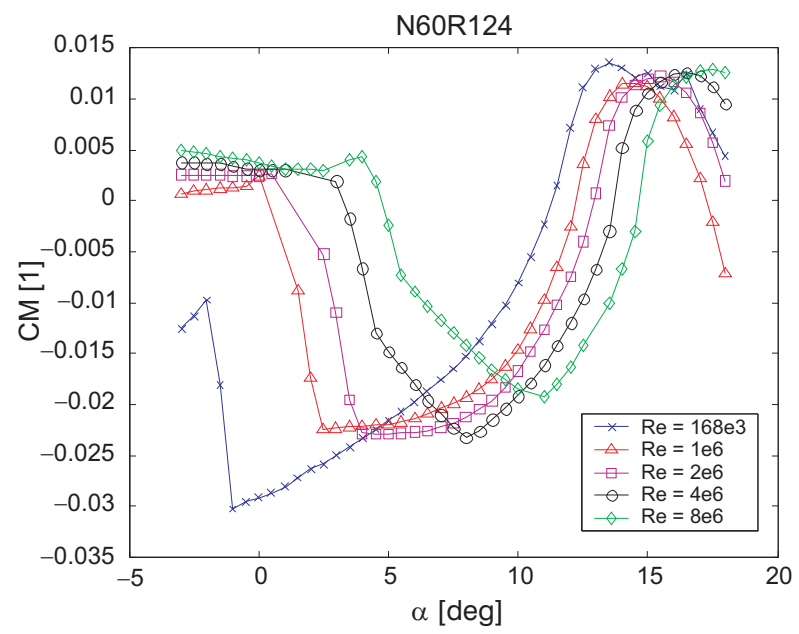

Fig. 7: Computed moment coefficient curves

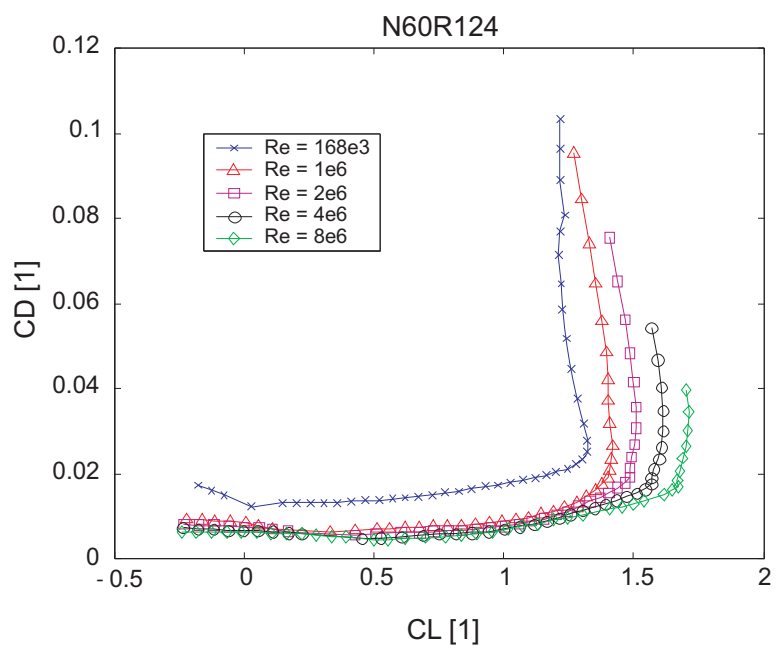

Fig. 8: Computed polars

Airfoil N60R150

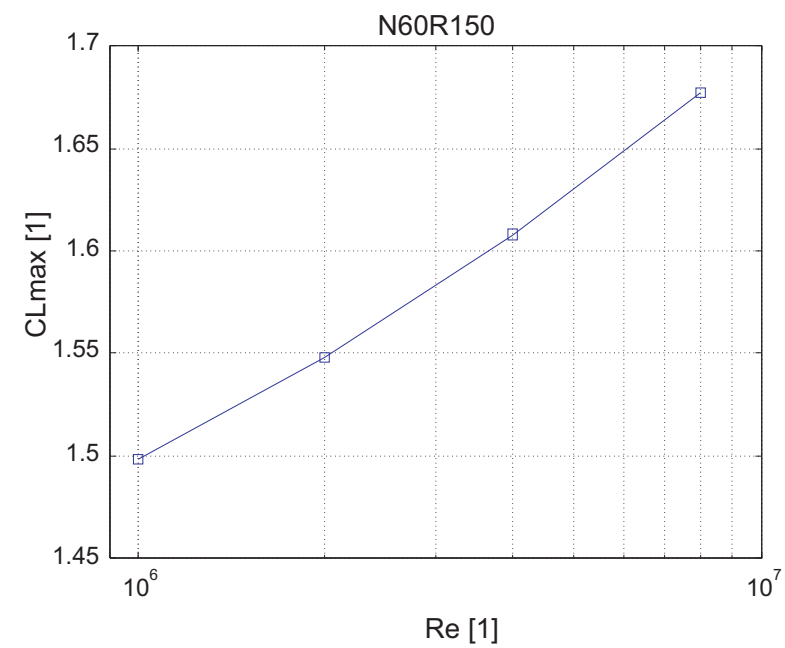

Fig. 9: Computed variation of $C L_{\max }$ with increasing Re number 
Table 3: Aerodynamic characteristics of N60R150, Re range

\begin{tabular}{|c|c|c|c|}
\hline $\begin{array}{c}R e \\
{[1]}\end{array}$ & $\begin{array}{c}\alpha_{0} \\
{[\mathrm{deg}]}\end{array}$ & $\begin{array}{c}C L_{\alpha} \\
{\left[\mathrm{rad}^{-1}\right]}\end{array}$ & $\begin{array}{c}C L_{\max } \\
{[1]}\end{array}$ \\
\hline 1000000 & -0.62 & 6.329 & 1.498 \\
\hline 2000000 & -0.74 & 6.541 & 1.548 \\
\hline 4000000 & -0.91 & 6.660 & 1.608 \\
\hline 8000000 & -1.02 & 6.707 & 1.677 \\
\hline
\end{tabular}

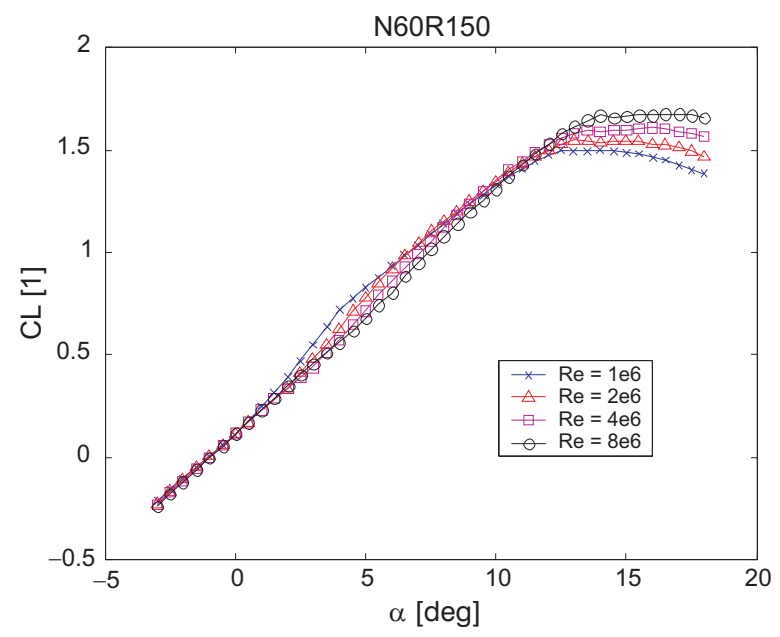

Fig. 10: Computed lift curves

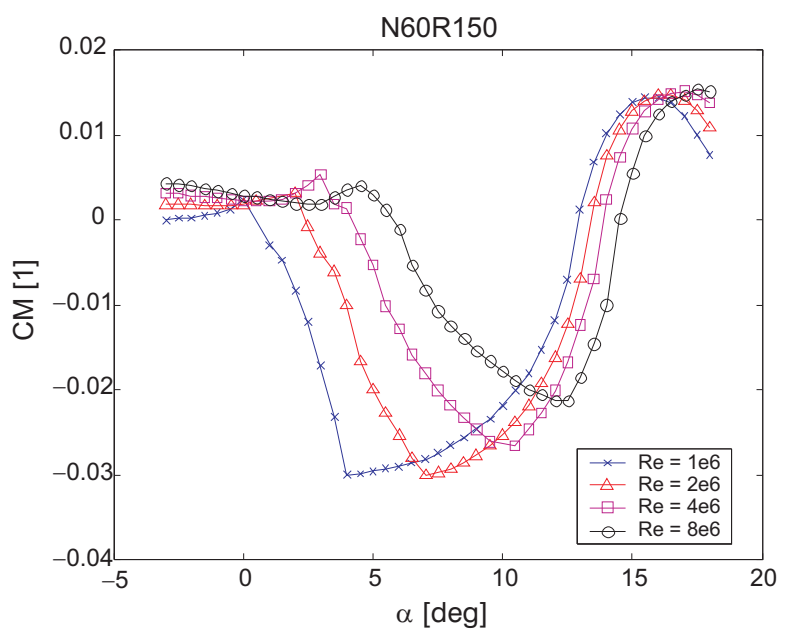

Fig. 11: Computed moment coefficient curves

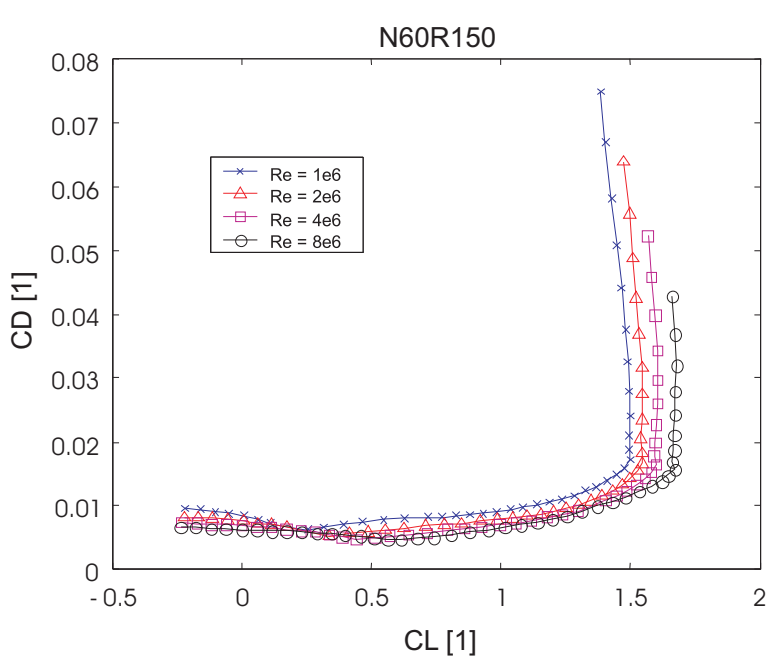

Fig. 12: Computed polars

\subsection{Discussion of results}

Airfoils N60R124 and N60R150 can be considered as suitable for tailless aeroplane due to the low moment coefficients values. In order to maintain the stability of the aeroplane a twisted wing tip section and the application of consistent deflection of the ailerons will be necessary. Experimental data and computation comparison was not applicable for the set up solution parameters due to unknown measurement conditions.

\section{Wing analysis}

The structural and strength design of the wing must take into account the distribution of aerodynamic parameters along the wing span. This task is quite simple for unswept wings and can be solved by a wide range of methods based on Prandtl lift line theory. But for more complex geometry this task becomes complicated. The L2k aeroplane has a variable sweep angle due to the parabolic leading and trailing edge (except ailerons).

\subsection{Used program}

PMW102 software developed at IAE was used to perform the computations. This package is based on the Prandtl theory of lift vortex (panel method) [3, 4]. The lift surface is replaced by the system of lift vortices distributed along the span and chord. Two conditions must be satisfied in order to determine the circulation - tangential flow at the panel surface and zero value of circulation at the trailing edge (Kutta-Joukowski condition). The model is divided into a finite number of trapezoidal panels with a horseshoe system of vortices. There is a constrained vortex at $1 / 4$ of the panel chord and free vortices flow from the constrained to the infinity parallel to the velocity vector. The flow vector must be tangential to the panel surface at a control point located at $3 / 4$ of the panel chord. This method is appropriate for swept wings, for lift surfaces with a small aspect ratio and likewise for complex geometry surfaces. Program allows the model geometry to be inputted only by the man curve of all bodies. Only a linear lift curve is considered. The PMW102 package 


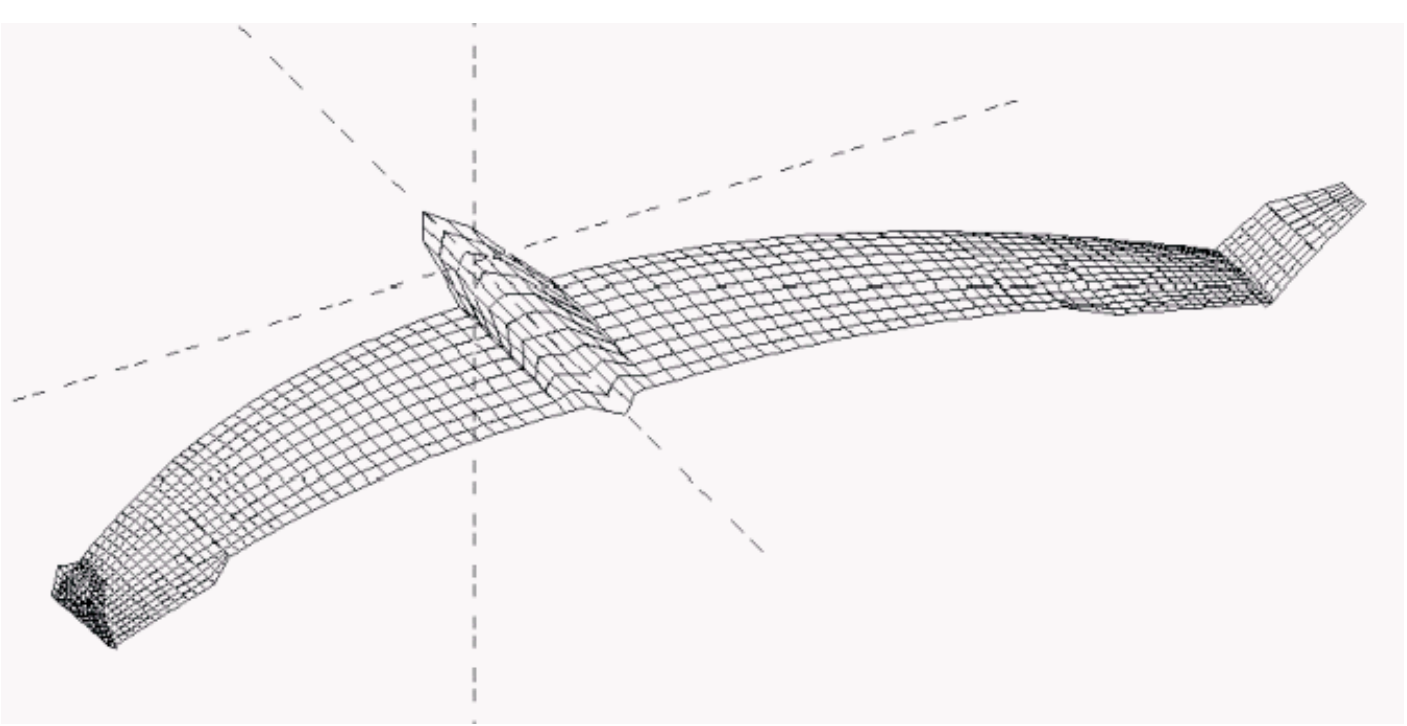

Fig. 13: Axonometric view of the computation model

involves a basic pre-processor, a solver and a post-processor, and is still under development.

\subsection{Model geometry}

The aeroplane was modelled by the mean curves of all bodies. This means that the aeroplane geometry was replaced by thin surfaces. The fuselage and winglets were also modelled to find out the impact on the flow field. The wing geometry had to be simplified because the pre-processor allows basic trapezoidal wing segments (blocks) to be modelled so the parabolic wing was replaced by 40 blocks with refinement at the tip area. A total of 1180 panels were used in 108 sections.

\subsection{Investigation process}

The first investigation was to determine the geometric twist angle of the wing tip airfoil $\left(\varepsilon_{\mathrm{T}}\right)$. It was derived from the condition that the difference between the airfoil max. lift coefficient and the local lift coefficient must be greater than 0.1 in the middle of the aileron span when maximum lift of the wing is reached. Three variants with twist angles of $-2,-3$, -4 degrees were tested and the case ZK 3 ( -4 deg.) was chosen as the best. This variant ensures that flow separation will develop at the wing root and will extend to the wing tip with increasing angle of attack. According to the results obtained a stall speed less than $65 \mathrm{kph}$ (by BFU) will be satisfied.

Table 4: Tip twist variations

\begin{tabular}{|c|c|c|c|c|c|}
\hline Var. & $\begin{array}{c}\varepsilon_{\mathrm{T}} \\
{[\mathrm{deg}]}\end{array}$ & $\begin{array}{c}C L_{\mathrm{kmax}} \\
{[1]}\end{array}$ & $\begin{array}{c}C M_{\mathrm{k}} \\
{[1]}\end{array}$ & $\begin{array}{c}\alpha \\
{[\mathrm{deg}]}\end{array}$ & $\begin{array}{c}\text { Stall Speed } \\
{[\mathrm{kph}]}\end{array}$ \\
\hline ZK 1 & -2 & 1.2846 & -0.012 & 17.6 & 56.246 \\
\hline ZK 2 & -3 & 1.2766 & -0.011 & 18.0 & 56.421 \\
\hline ZK 3 & -4 & 1.2139 & -0.008 & 18.0 & 57.861 \\
\hline
\end{tabular}

Note: $C M_{\mathrm{k}}$ is computed towards the $y$ axis. The angle of attack is measured from the root chord.

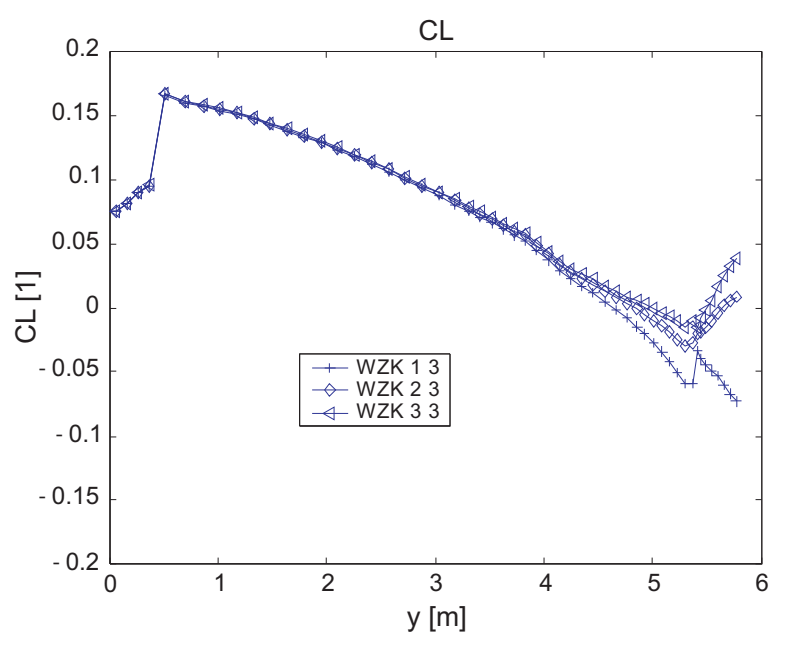

Fig. 14: Winglets variants, local $C L$ along span, angle of attack $2 \mathrm{deg}$

Table 5: Winglet twist angle variants

\begin{tabular}{|c|c|c|c|c|}
\hline Var. & $\begin{array}{c}\varepsilon_{\mathrm{w}} \\
{[\mathrm{deg}]}\end{array}$ & $\begin{array}{c}\alpha_{0} \\
{[\mathrm{deg}]}\end{array}$ & $\begin{array}{c}\mathrm{CL}_{\alpha} \\
{\left[\mathrm{rad}^{-1}\right]}\end{array}$ & $\begin{array}{c}\delta \mathrm{CL}_{\alpha} \\
{\left[\mathrm{rad}^{-1}\right]}\end{array}$ \\
\hline WZK 13 & 0 & 0.9692 & 4.2124 & 0 \\
\hline WZK 23 & 4 & 1.0830 & 4.1920 & -0.0204 \\
\hline WZK 33 & 6 & 1.1475 & 4.1755 & -0.0165 \\
\hline
\end{tabular}

The next investigation was to determine the geometric twist angle of the winglets $\left(\varepsilon_{\mathrm{w}}\right)$. Three additional variants of winglet twist angle were studied for the twist variant ZK 3 (Tab. 5). The variant WZK 13 that has the highest value of lift curve slope is the best from the induced drag point of view. Nevertheless, based on local CL distribution along the span (Fig. 14) the variant WZK 33 was chosen, because it gives more lift in the aileron area. 


\subsection{Computed cases for strength analysis}

The geometric variant WZK 33 was chosen as final to compute cases for the strength analysis. Five cases were selected on the manoeuvring and gust envelope (see Tab. 6). The lift curve was considered linear. This simplification can be used for the strength analysis.

Table 6: Envelope cases

\begin{tabular}{|l|c|c|c|c|c|c|}
\hline Case & Speed & $\begin{array}{l}\text { Speed } \\
\text { value } \\
{[\mathrm{kph}]}\end{array}$ & $\mathrm{n}$ & \multicolumn{2}{|c|}{$\begin{array}{c}\text { Aileron deflection } \\
{[\mathrm{deg}]}\end{array}$} & \multirow{2}{*}{ Note } \\
\cline { 5 - 7 } & & $\mathrm{R}$ & $\mathrm{L}$ & \\
\hline $\mathrm{P} 1$ & $V_{\mathrm{a}}$ & 112.17 & 4 & 0 & 0 & \\
\hline P2 & $V_{\mathrm{a}}$ & 112.17 & 1 & -30 & 20 & Full defl. \\
\hline P3 & $V_{\mathrm{d}}$ & 210 & 4 & 0 & 0 & \\
\hline P4 & $V_{\mathrm{d}}$ & 210 & 1 & -10 & 6.67 & $1 / 3$ defl. \\
\hline P5 & $V_{\mathrm{d}}$ & 210 & -1.5 & 0 & 0 & \\
\hline
\end{tabular}

Table 7: Summary of results

\begin{tabular}{|c|c|c|c|}
\hline Case & $\begin{array}{c}\alpha \\
{[\mathrm{deg}]}\end{array}$ & $\begin{array}{c}C L_{\mathrm{k}} \\
{[1]}\end{array}$ & $\begin{array}{c}C M_{\mathrm{k}} \\
{[1]}\end{array}$ \\
\hline $\mathrm{P} 1$ & 18.500 & 1.2920 & -0.0156 \\
\hline P2 & 5.617 & 0.2860 & 0.0092 \\
\hline P3 & 6.205 & 0.3823 & -0.0098 \\
\hline P4 & 2.410 & 0.0895 & 0.0011 \\
\hline P5 & -1.000 & -0.1362 & -0.0041 \\
\hline
\end{tabular}

The wing coefficients $C L_{\mathrm{k}}$ and $C M_{\mathrm{k}}$ (see Tab. 7) were computed from the distribution of local values along the span

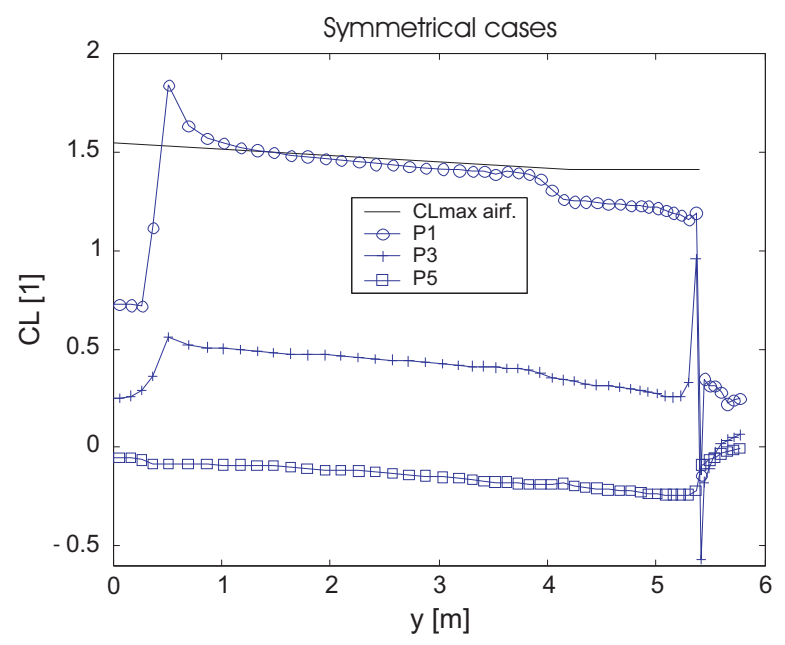

Fig. 15: Local CL along span, symmetrical cases

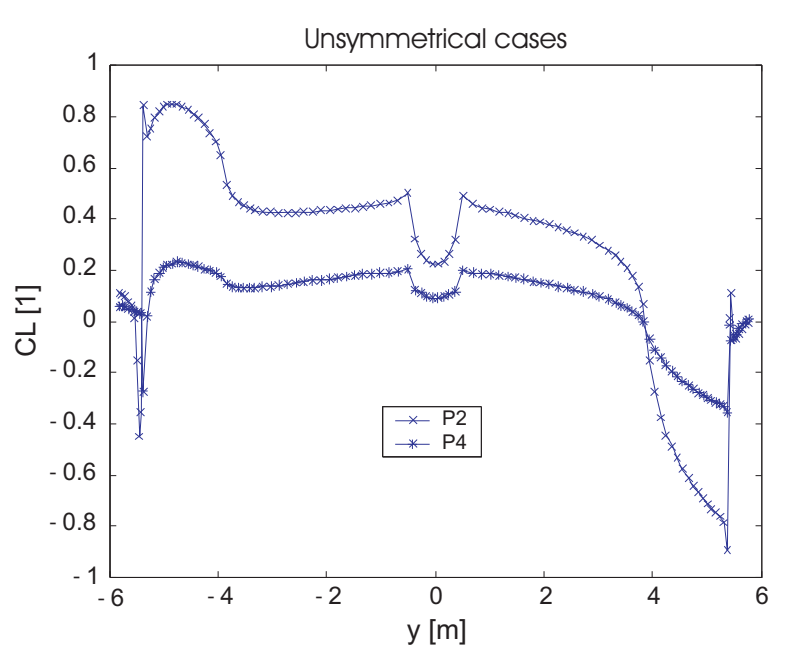

Fig. 16: Local $C L$ along span, unsymmetrical cases

using the trapezoidal method of numerical integration. The basic text output from the PMW102 programme with all operational load data is available.

\section{Conclusions}

Table 8: Results in linear area of lift curve

\begin{tabular}{|c|c|c|c|c|}
\cline { 2 - 5 } \multicolumn{1}{c|}{} & $\begin{array}{c}\alpha_{0} \\
{[\mathrm{deg}]}\end{array}$ & $\begin{array}{c}C M_{0 \mathrm{as}} \\
{[1]}\end{array}$ & $\begin{array}{c}C L_{\alpha} \\
{\left[\mathrm{rad}^{-1}\right]}\end{array}$ & $\begin{array}{c}C M_{\alpha} \\
{\left[\mathrm{rad}^{-1}\right]}\end{array}$ \\
\hline WZK 33 & 1.1475 & -0.0053 & 4.1755 & -0.0286 \\
\hline
\end{tabular}

The main objectives of the project were successfully completed. The characteristics of the modified N60R airfoil were obtained and data for the strength analysis of the wing was determined. It was shown that relatively complex wing geometry should be analysed via the panel method approach. In the investigative process some problems occurred, such as data evaluation of the results from PMW102, because the development of this software is still in progress.

\section{References}

[1] Horejší, M.: Aerodynamika létajících modelio. Praha, Naše Vojsko, 1957

[2] Drela, M.: XFOIL User Guide. MIT Aero \& Astro Harold Youngren, Aerocraft, Inc., 2001

[3] Kuthe, A. M., Chow, Ch.: Foundations of aerodynamics. New York, John Wiley \& Sons, Inc., 1998

[4] Brož, V.: Aerodynamika nízkých rychlostí. Ostrava, České vysoké učení technické v Praze, 1990

Ing. Jan Friedl

phone: +420541143470

fax: +420541142879

e-mail: friedl@iae.fme.vutbr.cz

Institute of Aerospace Engineering

Brno University of Technology

Technická 2, 61669 Brno, Czech Republic 